\title{
A Formative Study of an E-book Instructional Model in Early Literacy
}

\author{
Kathleen Roskos, Karen Burstein, Byeong-Keun You, Jeremy Brueck, \\ Carolyn O'Brien \\ ${ }^{1}$ John Carroll University, Ohio, United States \\ ${ }^{2}$ Southwest Institute for Families and Children, Scottsdale, United States \\ ${ }^{3}$ The University of Akron, Akron, United States \\ Email: roskos@jcu.edu \\ Received August $4^{\text {th }}, 2010$; revised February $7^{\text {th }}, 2011$; accepted February $12^{\text {th }}, 2011$.
}

\begin{abstract}
The electronic book is a rapidly growing alter native to the conventional book even for very young children; however, empirical studies on e-books as curricular tools in early literacy development and instruction are rare. Few instructional designs have been developed and tested. This formative study investigates the potential functionality and usability of a prototy pe 4-component e-book instructional model in a small sample of preschoo 1 classrooms. Using qualitative analytic strategies, observational data of its components were examined to identify salient indicators and design features, and to assess its feasibility. Re sults yielded design inform ation on eac $h$ component: (1) e-book as a quality technology-mediated environment; (2) phy sical place criteria; (3) engagement indicators; and (4) instructional potential. Strengths and weaknesses of the four-component model design were identified for purposes of revisi on and stabilizing the model for further testing in a larger classroo $\mathrm{m} \mathrm{sam}$ ple.
\end{abstract}

Keywords: E-books, Preschool, Early Literacy

\section{Introduction}

For nearly everyone, the electronic book is a rapidly growing alternative to the conventional book even for v ery young children. Most major publishing ho uses and man y major libraries now offer e-book collections for young children, not to mention the recent 'apps' available from iTunes downloadable to iPods, iPads and iPhones. What the shift from pag e to screen might mean for young liter acy learners remains to be seen, although that the e-book has arrived in their world is abundantly clear. Equally uncertain is how the e-book 'fits' in the pr eschool classroom as a curr icular tool and an instructional $r$ esource (Teale, 2010). Here we are adrift even as e-books for childr en spread ever more widely into e veryday life. Re search is very needed at this junctur e to $b$ uild an evid ence $b$ ase around e-books for 'ed utainment' as w ell as early liter acy education and to offer principles and methods for e-book pedagog y in early childhood classrooms.

\section{What We Know}

In general, studies of e-book design show that children's first e-books are mediocre at best. Examining the technical design of early childhood e-books, (de Jon g \& Bus, 2003) developed an analytic method that rated digital elements of e-b ook construction. Coding a corpus of 55 Dutch commercial e-books for features of multimedia, interactivity, print quality and quality of "hotspot" click locations, their analysis revealed generally weak designs in this corpus with many e-books containing low quality $\mathrm{m}$ ultimedia additions, 1 imited child -text in teractivity, and hotspots irrelev ant to the stor y lin e. Subsequent studies corroborate the lackluster quality of most e-books available for young children across cultures, reflecting what might be termed overall 'gard en variety' desi gn (Roskos, Brueck, \& Widman, 2009; Korat \& Shamir, 2004).

Still, a growing body of primarily lab-based research points to the poten tial of well-d esigned e-books for supporting and influencing young children's e merging lit eracy skills. In a series of studies $r$ ooted in Paiv io's dual- coding theor y (Pav io, 1986; Verhallen \& co lleagues, 2006), for example, found that children lagging in language skills benefited from e-books with rich visualizatio ns and sounds and music. Red undancies in these features in the e-book $d$ esign appeared to mobilize children's mental e nergy and to r e-invigorate th eir mental effor $t$, which led to improved story comprehension. Other researchers have obtained similar find ings - when e-book design features draw chi ldren's attention to words, the y learn words (S egers, 2009). When design emphasizes emergent literacy skills (e.g., phonological awareness), th ey learn thes e skills (Sham ir \& Korat, 2009). E-books, in sum, show promise as instructional tools that may go beyond the power of traditional storybooks.

But empirical studies on e-books as curricular resources in early liter acy instruction are presently rar e. Although some preliminary research shows, for example, th at kindergarteners that received mobile device rea ding interventions profited, demonstrating gai ns in th eir be ginning reading skills (Fishburn, 2008). The pro blems and edu cational ef fects of importing e-book technolo gy (to uch scr een computers, in teractive white boards, $m$ obile dev ices) in to the e arly literacy progr am in 
classrooms have largely gone unexamined - which is not to say that practical efforts have not been tried in classrooms.

\section{Description of the Study}

E-books will likely be a part of future early childhood classrooms, and in light of the th in evidence base on the ir role in curriculum and instruction, we u ndertook a formative study to investigate what e-book ped agogy for early literacy might look like in the early childhood classroom (Reigeluth \& Frick, 1999). We approached our research from a design perspective-much like an eng ineer - creating a prototype model for implementation in the classroom and testing it to begin a winnowing process that informs the edu cational design (e-book s in pr eschool for purposes of early literacy instruction) and identifies design features th at ar e fe asible and preferable in a $\mathrm{n}$ ins tructional model (Collins \& Bie laczyc, 20 04; Zaritsky, Flowers, Rogers, \& O’Neill, 2003).

At this early stage of proto type creation, we conceptualized an e-book instruction al model th at was pur posefully under-specified to allow a wide-angle view of wha t it takes and what happens when e-book technology is inserted into the preschool classroom. The model c onsists of fo ur components grounded in e-book studies (McKenna \& Zucker, 2009) and the knowledge base on early literacy instruction for young children (National Early Literacy Panel, 2008).

- The e-book as a technology-mediated environment

- The physical place of e-book reading in the classroom

- Engagement in e-book reading for small groups and individuals

- $\quad$ Explicit instruction using e-books

Our res earch objectives were to observe, def ine the salient attributes, and $\mathrm{r}$ ate the fun ctioning of each component in situ toward the go al of framing a model for $r$ eplication and furth er testing. To this purpose we em ployed a qua litative appro ach that focus ed on sorting, cluster ing, and aggregating observ ational data to derive quality indicators and design features.

\section{Method}

\section{Sites and Participants}

The model was implemented in four Ear ly R eading First classroom sites, two of which were located in the Midwest and two in the Southwest region of the United States. Early Reading First is a federally funded program that emphasizes sciencebased instruction in early language, cognitive, and pre-reading skills pr imarily serving poor children (U. S. Department of Education, 2008). A convenience sample was u sed consisting of a volunteer teacher and three children per site. (See Table 1.) It should be no ted that Site 4 served majo rity special $n$ eeds children.

\section{Procedures}

The design process unfolded in four phases over a six-month period as described in Figure1. Phase one involved setting design for small g roup and solo e- book reading in the classroom environment. Feasibility studies were conducted in phases two and three to gather data on the functionality (purpose and capacity for achieving learning outcomes) and usability (ease of adoption and use in the setting) of the model components. Data were an alyzed in phas e four to identify design strengths and weaknesses and to frame the model for further testing.

Phase One. The design $p$ rocess in phase on e yielded three outcomes that set the stage for implementation of the model in the sites: (1) a list of 68 mixed-genre e-books for e-book selection; (2) set-up specifications for an e-book nook in the classroom; and (3) an onlin e tutorial for teacher users. Access and cost factors influenced the titles included in the e-book collection. Subscription rates for some e-book sources are less costly than others and access to some e-book sour ces is limited on mobile devices, such as iPod to uches. Equipment, furnishings and space allocation were deter mining factors in the $b$ asic design of an e-book nook. (See Figure 2) The evidence base on physical environment design in early childhood classrooms also informed e-book nook specifications (Greenman, 1998; Moore, 2001). A short online tutorial was produced to demonstrate how to use the equipment and model shared reading with an e-book.

Phases Two and Three. An 8-week feasibility study was conducted to observe the implementation of the model in the four sites. Teachers were asked to make arrangements for the e-book nook in the ir classrooms; to plan for e-book reading sessions for approximately 15 minutes 2 ti mes per week; to select an e-book from a pre-selected list of eight titles for

Table 1.

Participant Demographics.

\begin{tabular}{|c|c|c|c|c|}
\hline \multirow[t]{2}{*}{ Classroom Site } & \multicolumn{2}{|c|}{ Teacher } & \multicolumn{2}{|c|}{ Child Sample $\mathrm{n}=3$ per site } \\
\hline & Years of Experience & Degree & Mean Age in months & $\begin{array}{c}\text { Mean PPVT Standard } \\
\text { Score }\end{array}$ \\
\hline 1 - Midwest & 16 & Associate & 54 & 97 \\
\hline 2 - Midwest & 12 & Associate & 50 & 96 \\
\hline 3 - Southwest & 14 & Elem. Ed & 57 & 84 \\
\hline 4 --Southwest & 2 & Special Ed & 44 & 69 \\
\hline
\end{tabular}

Note: PPVT-III: Peabody Picture Vocabulary Test (Dunn \& Dunn, 1997).

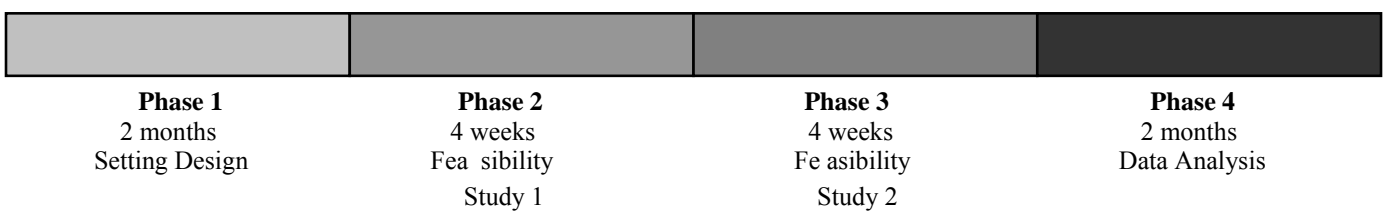

Figure 1.

Time Frame of the Study. 


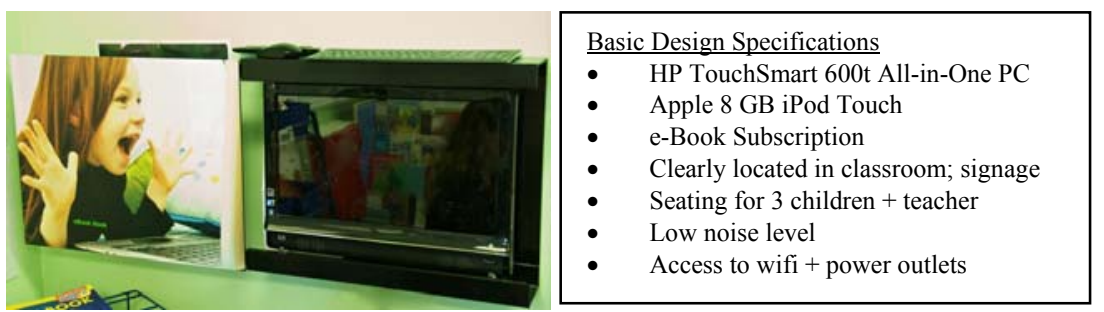

Figure 2

E-book nook Design.

repeated reading each week; and to follow an instructional protocol for teaching children target vocabulary words pre-selected from the e-book set. Research on direct vo cabulary instruction was used to $\mathrm{d}$ evelop the instruction al pro tocol (Roskos \& Burstein, 2009; Biemiller \& Boote, 2006; Silverman, 2007) and select vocabular y words for inst ruction (Roskos et al., 2008 ; Beck, McKeown, \& Kucan, 2003; Biemiller \& Slonim, 2001).

A pool of $80 \mathrm{v}$ ocabulary word s from the e-book set $\mathrm{w}$ as identified for direct instruction, using a 2-6-2 'rule of thumb': $20 \%$ basic con cept words; $60 \%$ root words; $20 \%$ sophisticated words. Vocabulary instruction consisted of a say-tell-do routine where teachers $(\mathrm{T})$ and children $(\mathrm{C}) \mathrm{s}$ ay a target word, $\mathrm{t}$ ell a child-friendly meaning of it, and do a gesture related to word meaning if appropriate. For ex ample, T say s: I say shovel; we say: shovel; T tells: A shovel, is a tool with a handle. We dig with it. Children tell one another [as best as they can]: Shovel is a tool with a handle. We dig with it. T shows with gestures: Let's dig with o ur shovel. Child ren show gestur es of digging with a shovel. Teachers were guided to use the say-tell-do routine before reading the e-book; during reading as appropriate; and to briefly review words after read ing in each e-book session.

The in itial 4 -week implementation was focused on e-book reading in small groups; the second on small group e-book reading was followed b y solo reading of the same story on the mobile $d$ evice. Two debr iefs with teacher $p$ airs wer e conducted-one at the 4-week midpoint and the other at the end of the 8-week period.

Videotaped obs ervations of e- book reading s essions were made using the web-cam on the All-in-One-Touch Smart PC to capture children's behaviors and a F LIP camera operated by a literacy coach to cap ture teacher beh aviors, tot aling 15 hours. Debriefs were conducted for approximately 1 hour using adobe acrobat and were audio taped. Teachers regularly used a one-page lesson plan form to r ecord week ly planning for the e-book sessions. Pre/post measu res on ch ildren's learn ing of target vocabu lary used a Curr iculum-Based De cision Measure (CBDM) approach developed by the researchers (Ergul, Burs tein, \& Bryan, in press).

Phase Four. During and following the feasibility study, data were processed using Carney's ladder of abstraction as a guide (Carney, 1990). Our analytic goal was to formatively assess the functionality of the model in the preschool lear ning environment and to gauge its potential usability in early literacy practice. Initially videotaped data of the e-book ses sions were uploaded into NV ivo 8 (QSR In ternational, 2 007), qu alitative analysis software, and org anized into a priori nodes representing bro ad categories of instru ctional ac tivity: organization, support, and affect. Each 'tre e node' was rep eatedly scann ed for salient indicators in each category, each indicator referred to as a 'chi ld.' S alient indi cators in ea ch category were lab eled and organized with initial d escriptors in to a set of indices for queries. (S ee appendix.) $\mathrm{W}$ orksheets for calculating the presence/absence of teaching actions per the vocabulary instruction protocol wer e d eveloped. Debr iefings were su mmarized into research memoranda. Lesson plans were reviewed or marked for evidence of planning before, during and after each e-book session. E-book qu ality w as summarized using a $\mathrm{r}$ esearch-based evaluation (Roskos, Brueck, \& Widman, 2009).

Following this initial level of abstraction, observational data were n ext re-or ganized and ag gregated to det ermine frequ encies of salient indicators in each componen $t$ and discern patterns. E-books were examined for evidence of research-based design features related to book assistants (e.g., start/stop/pause buttons), m ultimedia il lustrations, print, and i nteractivity (d e Jong \& Bus, 20 03). Physical design cr iteria were used to examine video/photo samples of the e-book noo $\mathrm{k}$ as a ph ysical place in the pr eschool classroom, including lo cation, signage, space allocation, acoustics and access to e-books (Roskos, 2008; Greenman, 2005). To gain a w ide-angle view of engag ement and instruction during e-book s essions, videotaped data were examined for indices in two ways. Presence of salient indicators in the bro ad ca tegories of a ctivity was id entified a 1 -m inute intervals in a s ub-sample of e- book sessions ( 8 per teach er counter-balanced for e-book session) and fidelity to the instructional pro tocol was examined at 30 -second in tervals on all e-book sessions. Th ese data were cross-referenced with teachers' comments in debriefs and their lesson plans.

Adapting a ty pological analy tic strategy (Lofland, 1971) observational data on each component were further abstracted into higher order categories of fun ction and use in the form of ratings based on a rudimentar y $0-3$ rating scale to repres ent evidence of pres ence $(0=$ no pr esence; $1=$ low presence; $2=$ moderate presence; $3=$ high presence) of indicators. Similar to Consumer Reports, $r$ atings $w$ ere organ ized into matrices for purposes of assessment.

\section{Results}

\section{E-book Quality}

Table 2 summarizes the ratings of e-book titles used to 'test' the $\mathrm{m}$ odel rel ated to pres ence of book assistant $\mathrm{s}$, m ultimedia illustrations and print, and interactivity as qua lity indicators. A signature design feature of e-books multimedia had a moderate presence in the set as did book assistants, but interactivity design $f$ eatures $f$ ell into the low rang e. $D$ esign fe atures w ere strongest in the folk tale (Jack and the Beanstalk), and weakest in two narratives (Mike and the Bike and Mud Puddle), and one informational bo ok (Diary of a Spider). The total mean rating of 1.75 suggests an overall $g$ arden-variety e-book design that may detract from the over all functionality and usability of the 
Table 2

Rating of Key Features of E-book Quality.

\begin{tabular}{|c|c|c|c|c|}
\hline Book Title & & Design Features & & Mean \\
\hline & Book Assists & $\begin{array}{l}\text { Multimedia Illus- } \\
\text { trations and Print }\end{array}$ & Interactivity & \\
\hline Bugs, Bugs, Bugs & $3(67 \%)$ & $2(60 \%)$ & $1(17 \%)$ & 2.00 \\
\hline How Zebras Got Their Stripes & $3(67 \%)$ & $2(60 \%)$ & $1(17 \%)$ & 2.00 \\
\hline Diary of a Spider & $1(33 \%)$ & $2(60 \%)$ & $1(17 \%)$ & 1.33 \\
\hline Jack and the Beanstalk & $3(67 \%)$ & $2(60 \%)$ & $2(50 \%)$ & 2.33 \\
\hline Fire Station & $1(33 \%)$ & $2(60 \%)$ & $1(17 \%)$ & 1.33 \\
\hline Mike and the Bike & $1(33 \%)$ & $3(80 \%)$ & $0(0 \%)$ & 1.33 \\
\hline Mud Puddle & $1(33 \%)$ & $3(80 \%)$ & $1(17 \%)$ & 1.67 \\
\hline Subway Ride & $3(67 \%)$ & $2(60 \%)$ & $1(17 \%)$ & 2.00 \\
\hline Total Mean & 2.00 & 2.25 & 1.00 & 1.75 \\
\hline
\end{tabular}

Percentage Benchmarks

$3=67-100 \% ; 2=34-66 \% ; 1=1-33 \% ; 0=0 \%$

model in $\mathrm{t}$ erms of e arly literacy learning outcomes. Design features included the fund amentals of e-books for young children, namely basic e-book assistants (start-stop features), animated illustrations and print highlights (largely at the sentence level), music, and voice narr ation, bu t few o pportunities to interact with the content or text (e.g., hotspots).

\section{Physical Place}

Ratings of the e-book nooks as distinct settings in the classroom si tes $p$ er the $p$ hysical de sign cr iteria are $d$ isplayed in Table 3 . Analysis of the matrix data points to relatively weak implementation of this compone nt in the built environment with a total mean of 1.3. Signage, for example, was totally absent in all sites, which may reflect a lack of signage generally in the preschool environments. Access to the inter-net and power sources was also very weak, and likely interfered with consistent quality in the e-book read ing sessions. Features of setting location and s patial arr angement and app eal were a lso in the low range, and again may reflect the broader design qualities of the settings. Attention to acoustical features showed the highest rating, perhaps because the teachers need ed to ensure children could hear the e-book narration during e-book reading sessions. Overall, the poor showing of $\mathrm{ph}$ ysical $\mathrm{pl}$ ace $\mathrm{c}$ riteria is di sappointing $\mathrm{s}$ ince t eachers s howed a $\mathrm{g}$ enuine e agerness to $\mathrm{cr}$ eate the e-book nook s in their classrooms. More explicit guid ance and examples may be needed to help teachers envision what an e-book nook might look like in the physical environment.

\section{Engagement}

Four data sources were clustered to $r$ ate the presence of teacher-child engagement durin $g$ the e-book shared $r$ eading sessions: (i) te acher-child motor beh aviors at the tou ch scre en (e.g., poin ting); (ii) children's facial g estures during e-book reading (e.g., s miling); (iii) teacher-child control of the e-book reading on the touch screen; and (iv) children's attention indicated by directional eye gaze toward the touch screen. Frequencies in each cluster were calculated based on the video observational data cod ed at 1-minute in tervals; arbitr ary ben chmarks were established to ra te engagement. $T$ hese data a re summarized in Table 4. It is important to note that the length of e-book sessions in classroom 2 were subs tantially shorter than those in the other sites, on average about 12 minutes long, thus reducing the opportunity for demonstrations of engagement. Th at classroom 4 served only special needs children should also be noted.

The strongest evidence of this component is demonstrated in facial $g$ estures that ind icate children's positiv e responses to screen content. The y fr equently s miled, contemplated, and gazed int ently at the $\mathrm{s}$ creen a cross e-book $\mathrm{r}$ eading sessions, suggesting th eir interest in the stories. Motor $b$ ehaviors als o provide strong evidence of engagement on the part of participants where po sitive types are high and neg ative types low. Incidences of pointing and sitting still predominated over those of wiggling and shifting about 'as if' unin terested. Children's focal attention to teacher and screen also provides evidence of moderate-to-high eng agement in the e-book $r$ eading across sites.

The weakest evidence of engagement involv ed shared control of the e-book screen. This indicator of engagement did not appear well org anized or man aged at th is point. Several teachers reported that asking children to manipu late the con trols at the tou ch screen proved disruptive, div erting children's attention from the st ory line. This, however, represents a neg ative design feature o f this component . Children's interactive participation, such as finger-tracking print, pointing to words and page-turning, is a staple of the shared book instructional routine (Mason, Peterman \& Kerr, 1989 ) because it has been found to develop children's knowledge of print conv entions which are foundational in the learn- to-read process (Morris, 1992). Shared control of th e e-book $r$ eading scr een, therefore, is a critical design factor that needs to be addressed and embedded in the model.

\section{Instruction}

The model lim its ins truction $t o$ empirical $t$ echniques th at support essential ear ly literacy skills (Nation al Early Literacy Panel, 2008). Instruction, therefore, is defined largely by fidelity to scien tifically proven and promising instruction al procedures and sequences (See, for example, p 14 of guidelines for teaching phon emic aw areness (Vau ghn \& Lin an-Thompson, 2004). The prototy pe model in this study used a direct instruction vocabulary sequence referred to as say-tell-do to 'test' the viability of the instruction co mponent in the classroom sites (Roskos \& Burstein, 2009). The procedure includes 12 teaching actions before, during and aft er s hared reading that guide instruction. In addition to evidence of fide lity to the instructional procedure (12 $t$ eaching a ctions), obs ervational data on $\mathrm{m}$ ean length of sessio $n$, the percent of teacher explanations of target words during sessions and ch ild use of target words dur ing sessions were calculated and rated to assess ho w well the instruction component fun ctioned in the e-book shared $r$ eading 
Table 3.

Physical Place Criteria Ratings by Classroom Site.

\begin{tabular}{|c|c|c|c|c|c|c|}
\hline \multirow[t]{2}{*}{ Site } & \multicolumn{5}{|c|}{ Design Features } & \multirow[t]{2}{*}{ Mean } \\
\hline & Location & Signage & Space & Acoustics & Access & \\
\hline Classroom 1 & 1 & 0 & 1 & 3 & 1 & 1.2 \\
\hline Classroom 2 & 2 & 0 & 1 & 2 & 1 & 1.2 \\
\hline Classroom 3 & 2 & 0 & 2 & 2 & 1 & 1.4 \\
\hline Classroom 4 & 2 & 0 & 2 & 2 & 1 & 1.4 \\
\hline Total Mean & 1.75 & 0 & 1.50 & 2.25 & 1.00 & 1.3 \\
\hline
\end{tabular}

Criteria Rubric

Location: 3 = clearly defined enclosure; 2 = somewhat defined; 1 = poorly defined; $0=$ no enclosure.

Signage: 3 = clear signage using print $\&$ picture; $2=$ printed sign; $1=$ picture; $0=$ no sign

Space: 3 = inviting with comfortable eating, light, color, graphics; 2 = attractive with adequate seating for viewing; adequate light; some coordinated color; 1 = basic setting with seating for viewing; poorly lit; uncoordinated color; $0=$ no pre-arranged seating.

Acoustics: $3=1$ low ex ternal sound levels; 2 = ordinary background noise; $1=$ high volume background noise; interruptions $0=$ p ersistent distracting, loud noises; interruptions

Access: 3 high-speed wifi acce ss; $>3$ power outlets a vailable; 2 = ade quate speed wifi or wire d; 2 power outlets a vailable; $1=$ s low speed wifi or wired acc ess; 1 power outlet available; $0=$ no wifi; extension cords

Table 4.

Ratings of Engagement by Classroom.

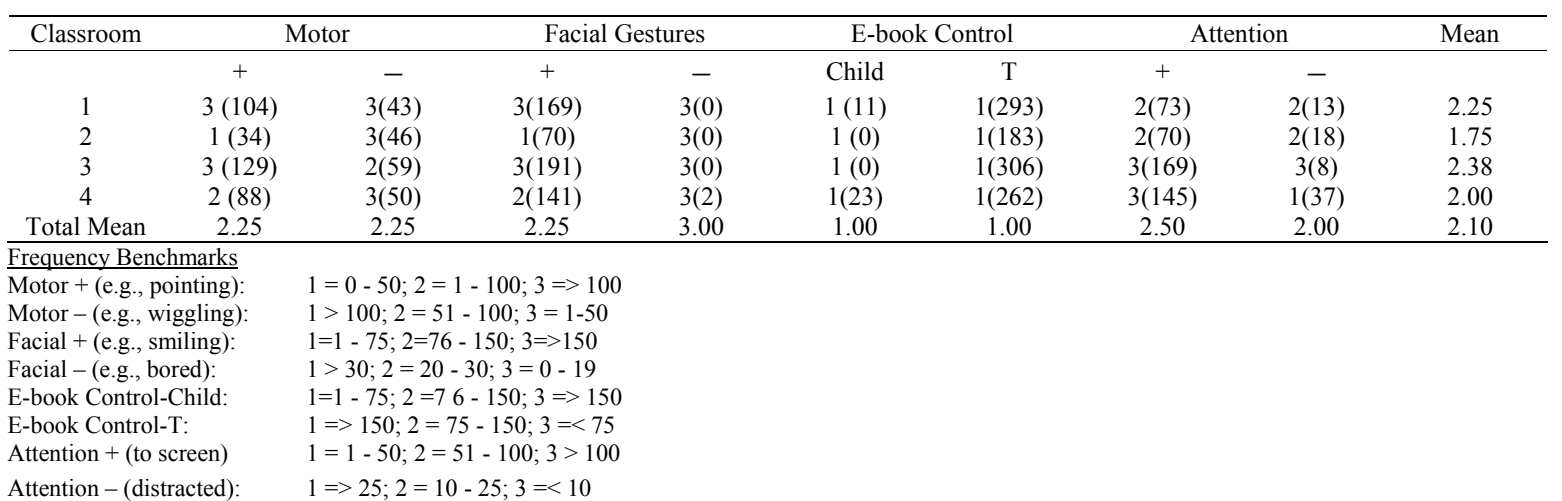

sessions. Ratings are shown in Table 5.

Implementation of th is component shows consid erable variability, particularly across indices of fidelity, session length and teacher explanations, which we might expect given the dynamics of instruction in real classrooms. Two pa tterns in the component ar e notable. With the exception of site 2, evid ence of fidelity to the instruct ional $\mathrm{p}$ rotocol-the 12 teaching actions - is moder ate to strong, which suggests th e poten tial strength of an explicit procedure as a des ign feature. But the generally weak presence of teacher language that supports word learning (explaining word meanings) also suggests that a protocol is an insufficient design feature, in and of itself. Individual teacher knowledge and skill is a powerful factor and needs to be consi dered in the desig $\mathrm{n}$. Mo re training and self-monitoring may need to be 'built into' the design to improve the functionality and usability of this component. Still, it is worth noting the strong showing of ch ild langu age in the functioning of th is component that provides further evidence of an explicit instructional protocol as a critical design feature that contributes to the overall fun ctionality of the model for achiev ing learning outcomes. As a proxy for functionality, the CBDM pre/post results support this conjectur e showing that children made vocabu lary gains in either r eceptive or expr essive voc abulary in the im plementation sites. (See Table 6)

\section{Discussion}

Given the deart h of research on e-book pedagogy in early literacy, we conceptualized and form atively tes ted a four-component model as an instructional framework for integrating e-books into the early literacy program. In this sm all-scale study, we im plemented our o riginal design concept of the mo del in four $\mathrm{p}$ reschool classrooms to observe the functionality and usability of its components with the goal of stab ilizing the model for more rigorous testing. Sa lient indicators of each compone nt were identi fied, orga nized at different le vels of a bstraction, and assigne $d$ ratings to yield an assessment of design strengths and weaknesses as a basis for $\mathrm{f}$ urther model de velopment. In brief, the design analysis revealed the need for bet ter quality e-books; more precise desi gn specifications for an e-book $\mathrm{n}$ ook in the classroo $\mathrm{m}$ setting; more e xplicit gui dance for c hild en gagement du ring e-book reading sessions; and s tronger teacher trai ning on 'how to' use instructional procedures and skills in shared e-book reading. Additionally, the successive analyses yielded a stronger and more parsimonious set of in dices for observing component function and use in subsequent de sign studies. En gagement indices, for exa mple, were collaps ed into four categorie s (motor; facial gesture; e-book control; attention) each with a fe w markers that can be organized into a more streamlined observation checklist. 
Table 5.

Ratings for Instruction by Classroom.

\begin{tabular}{ccccc}
\hline Classroom & $\begin{array}{c}\text { Fidelity to Instruc- } \\
\text { tional Protocol }\end{array}$ & Length of Session & $\begin{array}{c}\text { Teacher Language } \\
\text { (Explaining) }\end{array}$ & $\begin{array}{c}\text { Child Language } \\
\text { (Target Word Use) }\end{array}$ \\
\hline 1 & $3.00(550)$ & $3.00(17: 00)$ & $2.00(18 \%)$ & $2.00(44 \%)$ \\
2 & $1.00(260)$ & $1.00(12: 10)$ & $1.00(12 \%)$ & $2.00(41 \%)$ \\
3 & $3.00(535)$ & $2.00(14: 40)$ & $3.00(25 \%)$ & $3.00(55 \%)$ \\
4 & $2.00(437)$ & $3.00(16: 27)$ & $1.00(13 \%)$ & $3.00(54 \%)$ \\
Total Mean & $2.25(446)$ & $2.25(15: 04)$ & $1.75(17 \%)$ & $2.50(49 \%)$ \\
\hline
\end{tabular}

Frequency, Time and Percentage Benchmarks

Fidelity of Implementation: $\quad 3=>500 ; 2=300-500 ; 1=<300$

Length of Session: $\quad 3=>150 ; 2=13-16 ; 1=<3 \mathrm{~min}$

Teacher Language: $\quad 3=>20 ; 2=15-20 ; 1=<15 \%$

Child Language: $\quad 3=>50 ; 2=40-50 ; 1=<40 \%$

Table 6.

Child Performance Across Classrooms.

\begin{tabular}{|c|c|c|c|c|c|c|}
\hline Classroom & $\begin{array}{l}\text { Mean Pre Recep- } \\
\text { tive Assessment }\end{array}$ & $\begin{array}{c}\text { Mean Post Recep- } \\
\text { tive } \\
\text { Assessment }\end{array}$ & $\begin{array}{c}\text { Mean Receptive } \\
\text { Gain/Loss }\end{array}$ & $\begin{array}{c}\text { Mean Pre Expres- } \\
\text { sive } \\
\text { Assessment }\end{array}$ & $\begin{array}{l}\text { Mean Post Ex- } \\
\text { pressive } \\
\text { Assessment }\end{array}$ & $\begin{array}{c}\text { Mean Expressive } \\
\text { Gain/Loss }\end{array}$ \\
\hline 1 & 13.33 & 16.33 & 3.00 & 7.00 & 14.67 & 7.60 \\
\hline 2 & 14.00 & 16.67 & 2.67 & 9.33 & 8.00 & -1.33 \\
\hline 3 & 14.33 & 19.67 & 5.33 & 12.00 & 18.67 & 6.70 \\
\hline 4 & 9.00 & 8.00 & -1.00 & 6.33 & 9.67 & 3.30 \\
\hline
\end{tabular}

Several str engths in the func tionality and usab ility of the model components emerged. Func tionality of the instruction component, for example, appeared to be enhanced by the inclusion of an explicit instructional procedure, as demonstrated in fidelity to a direct vocabulary instruction protocol that appeared to yi eld gains in children's vocabulary across implementation sites. The relative power of this feature in the component design needs further testing. F unctionality of the eng agement component emerged in teacher- child motor behaviors at the screen, as wel 1 as childr en's ge nerally positiv e affe ct in the context. Usability was marked by a flexibility or 'play' in the components that allowed teachers to make adaptations in terms of e-book selection, ph ysical arrangements, and planning for and organ izing sessions to faci litate engagement a nd i nstruction.

Considerable design in each of the components remains, however, to st abilize th e m odel for $\mathrm{m}$ ore rigor ous testing in classrooms. One, a high quality set of e-books for preschoolers needs to $b$ e id entified and d escribed, including titles, brief annotations, source information and costs. Two, design specifications of the e-book nook need to be better articulated (e.g., equipment, space $n$ eeds, identity, technology access) and photo/graphic examples provided to aid teachers in setting up the e-book nook in their classrooms. Three, guidelines for engaging children at the screen dur ing e-book shared $r$ eading sessions need to b e developed in co llaboration with teachers to support children's active par ticipation in shared e-book r eading and to develop screen reading m otor skills. Four, onl ine professional development materials need to be developed that train teachers in the 'how to' of e-book reading (e.g., pacing, pausing, science-based protocols) and deep en their book-reading language facilitation skills, such as as king ques tions, clarifying con tent, extending id eas, etc). Brief computer-based tuto rials th at ou tline st ep-by-step 'how to' im plement the $m$ odel in the classroom would also be helpful. Following these improvements, further design-based research can be pursued on a larg er scale that dev elops a more functional and usa ble mode 1 in the pre school setting.

\section{Limitations}

Our results at this formative stage are limited by several factors. Technically, the poor quality of some videotaped observations (e.g., too much backgrou nd noise) rendered them unusable for coding. As a result, rele vant data may have been lost and not in cluded in the su ccessive analyses that yielded rating scores, thus $\mathrm{d}$ egrading the $\mathrm{d}$ esign inform ation. Site logisti cs were diff icult d ue to ext ernal factors (e.g., teacher sch edules, absences, mand atory meetings), which eroded the qu ality of training, site management and debriefings and likely compromised these obs ervational data for design purp oses. Analy tically, disciplined data analyses at successively higher lev els of abstraction proved very challenging in a collaborative research approach, which led to some miss-steps in coding and category-reduction that inf luenced th e emerging assessment of functionality and usability using a rating system. At times frustrating, this process nonetheless produced refinements in the set of indices for o bserving the model and guided design changes for the next phase of model development and testing.

\section{Conclusion}

The e-book represents a technol ogical adv ance in the book from a two-dimensional to a three-dimensional information tool, replacing the page with the screen and enlivening text with rich imagery, sound, and animation (Kress, 2003). Research on what this evolution means for early literacy learning is indeed young, but pioneer studies point to the potential of these new dynamic features for supporting children's emerging literacy skills and abilities (Segers, Nooijen , \& deMoor, 2006; Sh amir \& Korat, 2009; Verhallen, Bus, \& deJong, 2006). The important research 
task, however, is not only to u nderstand how these new ag e tools impact early literacy development and learning processes, but also to understand how to use them well in preschool early literacy education. Our e-book model is a des ign fr amework that moves in this direction and our ambitious g oal is to demonstrate 'proof of concept' that improves the instructional potential of $t$ he lit eracy-learning environment for te achers and children. We are at the start-point of this research agenda.

\section{References}

Beck, I. L., McKeown, M. G., \& Kucan, L. (2003). Taking delight i n words: Using or al language to build y oung children's vocabular ies. American Educator, 27, 36-46.

Biemiller, A. \& . Boote, C. (2006). An effective method for buildin g meaning vocabulary in primary grades. Journal of Educational Psychology, 98, 44-62. doi:10.1037/0022-0663.98.1.44

Biemiller, A. \& S lonim, N. (2001). Esti mating root word vocabulary growth in norm ative and advant aged populations: $\mathrm{E}$ vidence for a common sequence of vocabulary acquisition. Journal of Educational Psychology, 93, 498-520. doi:10.1037/0022-0663.93.3.498

Carney, T. F. (1990). Collaborative inquiry methodology. W indsor, Ontario: University of Windsor, Division for Instructional Development. doi:10.1207/s15327809j1s1301 2

Collins, A., Jose ph, D., \& Biela czyc, K. (2004). Design research: Theoretical and methodological issues. The Journal of the Learning Sciences, 13, 15-42.

de Jong, M. T. \& Bus, A. G. (2003). How well suited ar e electronic books for supporting literacy? Journal of Early Childhood Literacy, 3, 147-164. doi:10.1177/14687984030032002

Dunn, L. M. \& Dunn, L. M. (1997). Peabody Picture Vocabulary TestIII. Circle Pines, MN: American Guidance Publishers.

Ergul, C., Burstein, K., \& Bryan, T. (in press). Curriculum based decision-making: An assessment model to enhance early literacy skills of ELL preschoolers with and without special needs.

Fishburn, T. (2008). Mobile device early reading interventions in kindergarten classrooms, Ph. D. diss ertation, New Cas tle, DE: Wilmington University.

Greenman, J. (2005). Caring spaces, learning places: Children's environments that work, Redmond, WA: Exchange Press, Inc.

Korat, O. \& Sham ir, A. (2004). Do Hebr ew electr onic books dif fer from Dutch electronic books? A replication of a Dutch content analysis. Journal of Computer Assisted Learning, 20, 257-268. doi:10.1111/j.1365-2729.2004.00078.x

Kress, G. (2003). Literacy in the new media age. New York: Routledge.

Lofland, J. (1971). Analyzing social settings: a guide to qualitative observation and analysis. Belmont, CA: Wadsworth.

Mason, J., Peterman, C., \& Kerr, B . (1989). Reading to kinder garten children. In D. Strickland and L. Morrow (Eds.), Emerging literacy: Young children learn to read and write. (pp. 52-62). Newark, DE: International Reading Association.

McKenna, M., \& Zucker, T. (2009). Use of electronic storybooks in reading instruction. In A. Bus and S. B. Neuman (Eds.), Multimedia and literacy development. (pp. 254-272). New York: Routledge.

Moore, G. T. (2001). Childr en, y oung peo ple and the ir envir onment. Keynote address at the Fourth Child and Family Policy Conference, Dunedin, NZ.
Morris, D. (1992). Concept of $\mathrm{w}$ ord: A pivotal $\mathrm{u}$ nderstanding in $\mathrm{t}$ he learning-to-read process. In S. Templeton \& D. R. Bear (Eds.), Development of orthographic knowledge and the foundations of literacy: A memorial festschrift for Edmund H. Henderson, (pp. 53-77). Hillsdale, NJ: Erlbaum, Hillsdale.

National E arly L iteracy Panel. (2008). A scientific synthesis of early literacy development and implications for intervention. Washington, DC: National Institute for Literacy.

Paivio, A. (1986). Mental representation: A dual coding approach. Oxford, England: Oxford University Press.

QSR International (2007) NVivo 8. http://www.qsrinternational.com.

Reigeluth, C. M., \& Frick, T. W. (1999). Formative research: A methodology for creating and im provingdesign theories. In C. M. Reigeluth (Eds.), Instructional-design theories and models - A new paradigm of instructional theory (pp. 633-652). New Je rsey: L awrence Erlbaum.

Roskos, K. (2008). The benefits of going green. In S. B. Neuman (Ed.), In Educating the other America (pp. 333-346). Baltim ore, M D: Brookes Publishing.

Roskos, K. , Br ueck, J. , \& Widman, S. ( 2009). Dev eloping analy tic tools for e-book d esign in early literacy learning. Journal of Interactive Online Learning, 8, 2009. Internet Available: http://www. ncolr.org/jiol.

Roskos, K. \& Burstein, K. (2009). Attempting to level the playing field: A vocabulary intervention for at risk and special needs preschoolers. Paper presented at the Annual Meeting of the American Educational Research Association. San Diego, CA.

Roskos, K., Ergul, C., Bryan, T., Burstein, K., Christie, J., \& Han, M. (2008). Who's learning what words and how fast: Pr eschoolers' vocabulary growth in an early lit eracy program. Journal of Research in Childhood Education, 22, 275-290. doi: $10.1080 / 02568540809594627$

Segers, E. (2009). Learning from in teractive vocabulary books in kindergarten. In A. Bus \& S. B. Neuman (Eds.), Multimedia and literacy development, (pp. 112-123). New York: Routledge.

Segers, E., Nooijen, M., \& de M oor, J. ( 2006). Co mputer vocabulary training in kinder garten child ren with special needs. International Journal of Rehabilitation Research, 29, 343-345. doi:10.1097/MRR.0b013e328010f4e0

Shamir, A. \& Korat, O. (2009). The educational electronic book as a tool for supporting children's e mergent literacy. In A . Bus \& S. B. Neuman (Eds.), Multimedia and literacy development (pp. 168-181). New York: Routledge.

Silverman, R. (2007). A co mparison of thr ee methods of vocab ulary instruction dur ing $\mathrm{r}$ ead-alouds in kindergarten. The Elementary School Journal, 108, 97-113. doi:10.1086/525549

Teale, W. (2010). Discussant comments at the $17^{\text {th }}$ Annual Conference of the Society for the Scientific Study of Reading, Berlin, Germany.

U. S. Department of E ducation, Ed.gov. (2008). Early Reading Fir st. URL (last checked 31 January 2011) http://www2.ed.gov/programs/earlyreading/index.html

Vaughn, S. \& Linan-Thompson, S. (2004). Research-based methods of reading instruction. Alexandria, VA: ASCD.

Verhallen, M., Bus, A., \& de Jong, M. (2006). The promise of multimedia stor ies for kindergarten childr en at risk. Journal of Educational Psychology, 98, 410-419. doi:10.1037/0022-0663.98.2.410

Zaritsky, R., Kelly, A., Flowers, W., Rogers, E. \& O 'Neill, P. (2003). Clinical design sciences: A view from sister design efforts. Educational Researcher, 32, 32-34. doi:10.3102/0013189X032001032 


\section{Appendix}

Initial Set of Indices for Coding Observational Data

Node

Organization

Supports

Affect
Salient Indicators (Child)

Position

Location

Controls

Attention

Motor

Language

Personalization
Gestures

Language
Descriptors

Sitting

Kneeling

Laying

Standing

Chair

Floor

Pillow

Bench

Auto

Manual

Teacher

Child

Eye Gaze

Look

Pointing

Moving About

Directing

Explaining

Questioning

Extending

Feedback

Peer to Peer

Smiling

Clapping

Frowning

Contemplating

Puzzling

Being Scared

Expressive

Comments

Squeals

Noises

Curiosity

Interest

Self-talk 